\title{
Micro-turbine applied to seismology: towards a power supply safe from lightning
}

\author{
Davide Scafidi ${ }^{1}$, Francesco Roncallo ${ }^{2}$, Alberto Traverso ${ }^{2}$, Gabriele Ferretti ${ }^{1}$, Marco Pasta ${ }^{1}$, Mauro Pavan ${ }^{1}$, Simone \\ Barani $^{l}$, Daniele Spallarossa ${ }^{l}$ \\ ${ }^{1}$ DISTAV - Earth, Environment and Life Department, University of Genoa - Corso Europa 26, 16132 Genoa, Italy \\ ${ }^{2}$ SIT Technologies Srl, VIA XX Settembre 33, Genoa, Italy
}

\begin{abstract}
The present work aims to suggest an innovative solution for seismic monitoring stations' endurance. These stations are characterized by many different problems, such as lightning vulnerability, energy independence and noises disturbance. The suggested technology, for this type of application, is an improved bladeless turbo-expander patented by Nikola Tesla in the early $20^{\text {th }}$ century, the Tesla turbine.
\end{abstract}

\section{Introduction}

Seismic stations are generally installed in remote places, characterised by very low background noise. In such remote site, the seismic devices powered by electricity can be exposed to damage caused by electric surges, often produced by lightning. Voltage and current surges cause most of the damage to seismic equipment around the world [1][2], producing station failures that can compromise the functionality of a seismic monitoring system. Surge protections are probably the most used tools in preventing station failure even if they are not always effective. Fortunately, a direct hit by lightning causing equipment unrecoverable damage, despite the best protections, only rarely happens. Most lightning-related damages are caused by induction surges in cables, even when the source is at some distance from the station [3]. The effects of electric surges on seismic monitoring system have been directly observed on the Regional Seismic Network of North-Western Italy (RSNI), managed by the University of Genoa and active since 1963 [4]. Over decades, the main cause of instrumentation failure has been the lightning fall near seismic stations. Of note, in case of large thunderstorm, like the ones occurred on summer 2015, multiple stations have been damaged together, compromising the proper functioning of the seismic monitoring system.

Fig. 1 - Turbine components - (a) Rotor with disks, spacers and shaft (b) Disks with different central opening (c) Assembled Tesla turbine prototype with flywheel for magnetic braking (d) Stator element
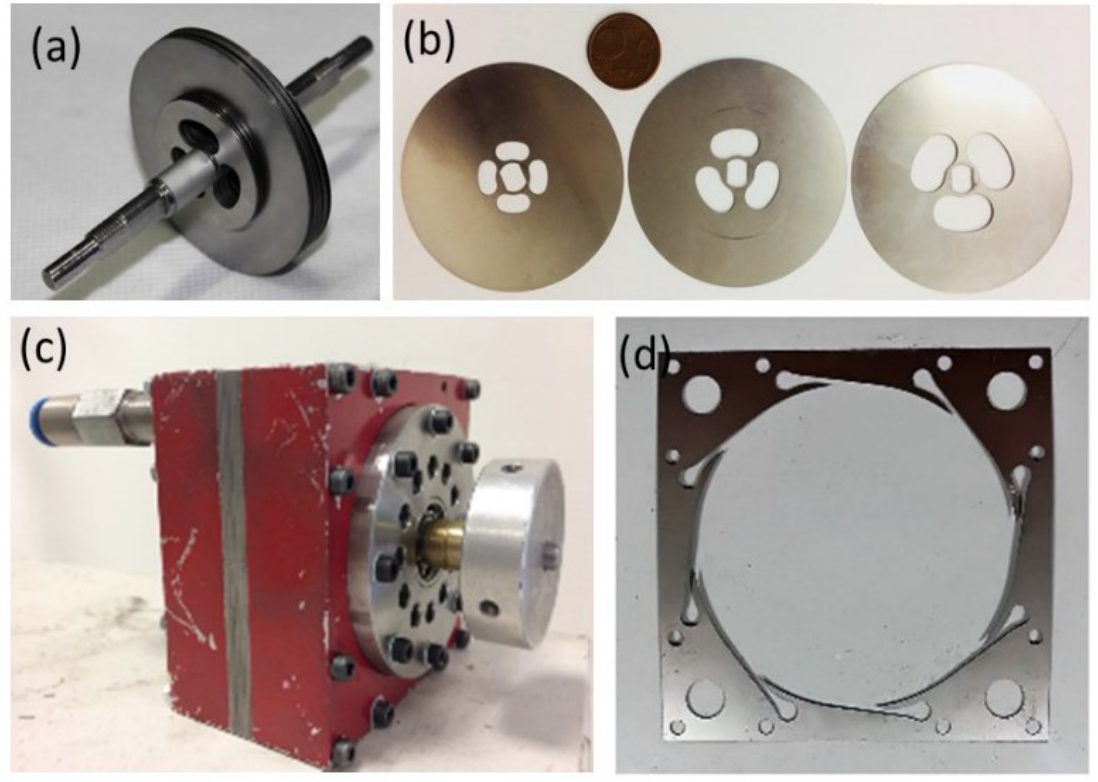

Besides the most common tool for lightning protection (good grounding system, surge protections, etc..), in many years of field experience, other mitigation measures have been investigated and applied by the RSNI staff. The most effective ones are the use of a optic fiber system between the seismic station and the transmission system, such as phone cable or cellular line, to electrically disconnect the two systems, and the use of a crystal plate between the seismic sensor and the ground to eliminate or mitigate induced currents coming directly from the ground.

Voltage and current surges could also come from the mains power supply. In this case, the only solution is to completely isolate the seismic station from mains power supply or to use alternative power supplies using, for example, photovoltaic panels. There are however situations where this strategy is not applicable (environmental restrictions, low daily sunlight, etc..). Another alternative power supply tested over years is based on the use of a fuel cells but the system has been discarded because of its weakness in cold environment and the need for frequent and expensive manual refuelling.

\section{Tesla turbine applied to remote seismic stations for a safe power supply}

In this work we present an innovative solution, that may become a benchmark for this type of application, represented by Tesla turbines (Fig.1) combined with pressurized fluid storages. This turbine is extremely versatile and adaptable, mainly thanks to its blade-less characteristics. This last point enables to use the turbine with any kind of fluid in order to 
guarantee an electric power production [5]. The most promising solution for seismic stations is undoubtedly referred to Tesla turbines coupled with compressed air storages: this system would guarantee a defined energy supply with defined duty cycles considering any environmental condition. A Tesla turbine for powering seismic was tested in order to verify its reliability and its efficiency also with its influence on the seismic recordings quality, considering that the vibrations produced by the turbine can alter the background noise level. The turbine is characterized by significantly low vibrations and few precautions can eliminate them. The chosen power size of the air prototype was $100 \mathrm{~W}$. The experimental set-up was diversified for different geometries, the promising one was considered as it follows in table 1 [6].

Table 1. Tesla characteristics and performance

\begin{tabular}{|c|c|c|c|c|}
\hline \multicolumn{3}{|c|}{ Disk diameter } & \multicolumn{2}{|l|}{$20 \mathrm{~mm}$} \\
\hline \multicolumn{3}{|c|}{ Gap between disks } & \multicolumn{2}{|l|}{$0.2 \mathrm{~mm}$} \\
\hline \multicolumn{3}{|c|}{ Disk number } & \multicolumn{2}{|l|}{10} \\
\hline Speed & $\begin{array}{l}\text { Mass } \\
\text { flow }\end{array}$ & $\begin{array}{c}\text { Pressure at } \\
\text { Nozzle } \\
\text { upstream }\end{array}$ & Efficiency & Power \\
\hline $\mathrm{rpm}$ & $\mathrm{g} / \mathrm{s}$ & barg & $\%$ & $\mathrm{~W}$ \\
\hline 40000 & 3.5 & 1.52 & $6.1 \%$ & 14.8 \\
\hline 40000 & 4.7 & 2.25 & $11.1 \%$ & 44.1 \\
\hline 40000 & 5.8 & 3.05 & $13.9 \%$ & 79.7 \\
\hline 40000 & 7.1 & 3.91 & $15.5 \%$ & 119.6 \\
\hline 40000 & 7.6 & 4.30 & $15.7 \%$ & 136.7 \\
\hline
\end{tabular}

Considering this as a starting point, also with the specific loads resulting from seismic monitoring activities, it was possible to suppose a correct duty cycle for the coupling of a Tesla turbine with a compressed air storage.

The main loads of a remote seismic stations consist of the load of the seismic instrumentation (sensor and acquisition system) plus the load of the transmission system. Standard modern seismic instrumentation generally has a power consumption around $2-5 \mathrm{~W}$, while the remote transmission system is of about $3-6 \mathrm{~W}$ for a cellular modem (GPRS/UMTS). In the most problematic installation sites concerning lightning risk, where an isolated power supply (i.e.: solar panels) could not be considered, often only the acquisition system is fed by batteries while the transmission system (less expensive) is fed by mains power line to save batteries and to enlarge the life-time of the seismic station. In this situation additional $0.5 \mathrm{~W}$ should be considered for a couple of wi-fi modules or $0.2-0.4 \mathrm{~W}$ for a couple of optic fiber modems, to electrically disconnect the two systems and reduce the potential damage of a lightning strike. Such instrumentation is not necessary if all the system (acquisition and transmission) is fed only by Tesla turbines, for a benefit of the system also in terms of streamlining. The complete average power consumption of the tested seismic station (Fig. 2) (sensor "Guralp CMG40" with digitizer "Lunitek Atlas": average power consumption of $3.1 \mathrm{~W}$ ) transmitting through an industrial cellular modem (Conell UR5: average of $3.5 \mathrm{~W}$ with GPRS transmission) is of about $6.6 \mathrm{~W}$.

Fig. 2 - Example of a seismic station - On the left there is the sensor and inside the box on the right there are the acquisition systems (Lunitek Atlas) fed by batteries, and the transmission systems (UMTS modem) fed by mains power supply with additional surge protections. The two systems are electrically disconnected through a pair of optic fiber modems
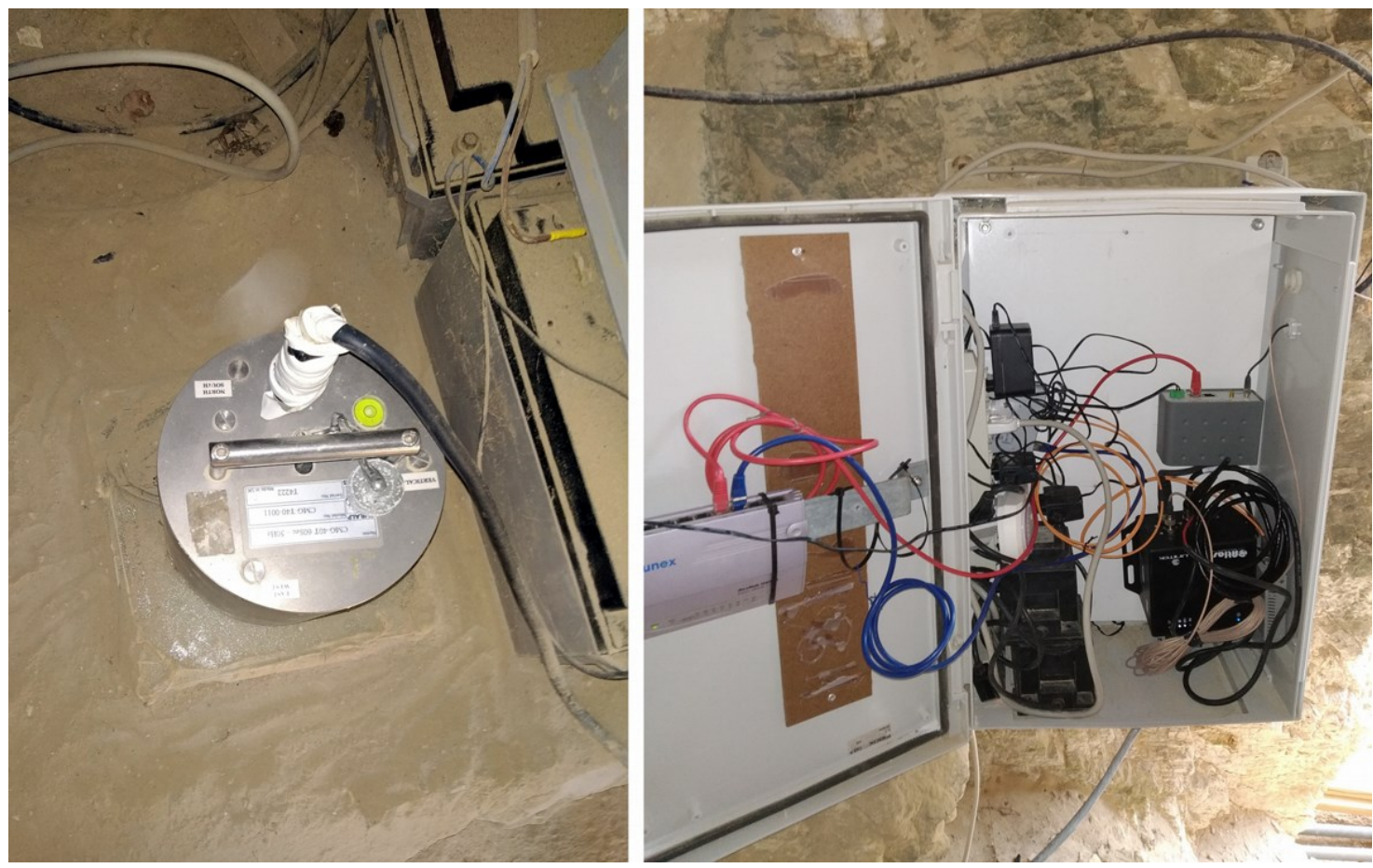


\section{Conclusions: usage scenarios}

Therefore, some scenarios were identified for an advantageous intermittent utilization of Tesla turbine to feed a backup battery pack suited for the described seismic stations. In the most promising scenario, the Tesla turbine is coupled with a pressurized air tank of about $0.9 \mathrm{~m}^{3}$. The considered battery pack is composed by 3 modules of $12 \mathrm{~V}$ lithium batteries at $65 \mathrm{Ah}$. Here below a schematic table with the main elements of this duty cycle.

Table 2. Usage scenario 1: characteristics of the power supply system

\begin{tabular}{ll}
\hline Air tank volume & $\mathbf{0 . 9} \mathbf{~ m}^{\mathbf{3}} \mathbf{( a t} \mathbf{1 0}$ bar $)$ \\
\hline Tesla air flow & $0.012 \mathrm{~m}^{3} / \mathrm{min}($ at $4.3 \mathrm{barg})$ \\
\hline Power produced & $130 \mathrm{~W}($ electrical conversion efficiency $96 \%)$ \\
\hline Target energy & $780 \mathrm{Wh}(1$ battery pack module $)$ \\
\hline Working time & $360 \mathrm{~min}$ \\
\hline Total station life time & $472 \mathrm{~h}(19.6$ days $)$ \\
\hline
\end{tabular}

In this scenario the turbine will extend the working condition of the seismic station of about 5 additional working days. Other two interesting scenarios are related to the doubling of the station endurance:

Table 3. Usage scenario 2: characteristics of the power supply system

\begin{tabular}{ll}
\hline Air tank volume & $\mathbf{2 . 6} \mathbf{~ m}^{\mathbf{3}}$ (at $\mathbf{1 0}$ bar) \\
\hline Tesla air flow & $0.012 \mathrm{~m}^{3} / \mathrm{min}($ at $4.3 \mathrm{barg})$ \\
\hline Power produced & $130 \mathrm{~W}($ electrical conversion efficiency $96 \%)$ \\
\hline Target energy & $2340 \mathrm{Wh}$ (full battery pack) \\
\hline Working time & $1080 \mathrm{~min}$ \\
\hline Total station life time & $709 \mathrm{~h}(29$ days $)$ \\
\hline
\end{tabular}

Table 4. Usage scenario 3: characteristics of the power supply system

\begin{tabular}{|c|c|}
\hline Air tank volume & $0.8 \mathrm{~m}^{3}$ (at 20 bar) \\
\hline Tesla air flow & $0.012 \mathrm{~m}^{3} / \mathrm{min}$ (at $4.3 \mathrm{barg}$ ) \\
\hline Power produced & $130 \mathrm{~W}$ (electrical conversion efficiency $96 \%$ ) \\
\hline Target energy & $2340 \mathrm{Wh}$ (full battery pack) \\
\hline Working time & $1080 \mathrm{~min}$ \\
\hline Total station life time & 709 h (29 days) \\
\hline
\end{tabular}

After the conclusion of the batteries life time, a recharge is needed, both from electrical and pneumatic points of view. The described system could also be supported by the presence of an air compressor to make totally independent the whole seismic station despite the battery pack life itself, still retaining the physical separation from any grid cable.

Such a safe power supply system could be easily applied not only to a remote seismic station, but also to any remote monitoring system with comparable power consumption.

\section{References}

[1] Castellano, M., Buonocunto, C., Capello, M., Caputo, A. (2002): A new standard for seismic station installation of the Osservatorio Vesuviano Surveillance Network (INGV, Napoli). Quaderni di Geofisica, vol. 25, pp. 1-20, http://hdl.handle.net/2122/2801

[2] Havskov, J., Ottemöller, L., Trnkoczy, A., Bormann, P. (2012): Seismic Networks. - In: Bormann, P. (Ed.), New Manual of Seismological Observatory Practice 2 (NMSOP-2), Potsdam: Deutsches GeoForschungsZentrum GFZ, pp. 1-65. DOI: http://doi.org/10.2312/GFZ.NMSOP-2_ch8

[3] Trnkoczy, A., Bormann, P., Hanka, W., Holcomb, L. G., Nigbor, R. L. (2009 online): Site Selection, Preparation and Installation of Seismic Stations. - In: Bormann, P. (Ed.), New Manual of Seismological Observatory Practice (NMSOP), Potsdam: Deutsches GeoForschungsZentrum GFZ, pp. 1-108. DOI: http://doi.org/10.2312/GFZ.NMSOP_r1_ch7

[4] University of Genova (1967): Regional Seismic Network of North Western Italy. International Federation of Digital Seismograph Networks. Other/Seismic Network. 10.7914/SN/GU

[5] Traverso, A., Barberis, S., Larosa, L., and Silvestri, P., 2018, "Reverse Cycle Machine Provided with a Turbine", World Patent WO2018/127445A1. 
[6] A. Renuke, A. Vannoni, A. Traverso, M. Pascenti, 2019, "Experimental And Numerical Investigation Of Small Scale Tesla Turbines", ASME paper GT2019-91352 